\title{
Does The Gender Of The Manager Affect Who He/She Networks With?
}

Irene Hau-siu Chow, (Email: irene@baf.msmail.cuhk.edu.hk), Chinese University of Hong Kong, China Ignace $\mathrm{Ng}$, University of Victoria, Canada

\begin{abstract}
Based on a sample of 72 managers from Hong-Kong and1032 associates identified by these managers, the results show that female managers network with other females for expressive support but when seeking instrumental contents, they network with male associates. We also found that females are less likely to approach female associates they have strong ties with but are more likely to approach similarly ranked colleagues. They are also unlikely to approach higher ranked female colleagues to network on instrumental contents. Taken together, these results imply that for female managers seeking instrumental support, they should focus on peer-relationships with other females as well as on male associates with whom they have strong ties with. From a stakeholder's point view, more attention should be paid to designing and implementing social policies and integrating a gender perspective into all public policies. This calls for setting up an integrated network of structure, mechanism and processes designed to arouse more gender-awareness, increase the number of women in decision-making role, facilitate the formulate of gender-sensitive policies and programs. Long-term strategies should be developed to build up women through personal growth process, promote integration and equality in the workplace.
\end{abstract}

\section{INTRODUCTION}

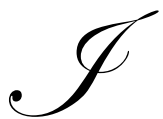

n spite of increased efforts by the corporate world to remove practices that prevent women from moving up the organizational hierarchy, women are still underrepresented in senior management positions in both the U.S. and elsewhere (Oakley, 2000; Adler, 1993). Several explanations have been put forward for this so-called "glass ceiling" phenomenon (Austen, 1993; Raggins et al., 1998; Oakley, 2000). One that has received considerable attention in recent years is the argument that women do not have the same access to career enhancing networks as men (Kanter, 1977; Morrison, White, \& Van Velsor, 1987). This proposition in turn led several investigators to examine gender differences in networks. Moore (1990) found that while males and females have similar network size, they differ in terms of their network composition, with females having more family members in their network. Ibarra $(1992,1997)$ uncovered further differences, showing that males prefer to network with other men on both expressive and instrumental contents while females choose other females for expressive contents only. Both males and females seek male associates when networking on instrumental contents. In other words, for instrumental purposes, males will seek same sex ties while females will seek cross-gender ties. The corollary is that there is no role for females to offer advice and provide influence to other women. Such conclusion, however, contradicts the view in the mentoring literature (Raggins and Cotton, 1991; Feldman et al., 1999) that women proteges should seek out female mentors to avoid the problems usually associated with cross-gender mentoring relationships.

The reason for the above contradiction, we argue, is due to the failure in the network analytic literature to control for those relational factors between egos (defined here as those seeking a networking opportunity) and associates (defined here as the target person of the ego) that can affect the preference of female egos to network with male associates. For instance, if one takes into account the managerial ranks of the associates, it can be argued that females may in fact prefer to network with high ranking females over similarly ranked males. Thus, in assessing whether women actually prefer to network with male associates, it is necessary to consider the influences of the associates' other characteristics. 
This study investigates the role of gender in workplace networks. It examines whether male and female managers in their choice of network associates differ in terms of their preferences for same sex associates, higher ranked associates and those with whom they have strong ties with. In addition, this paper also studies whether the preference for same sex associates is moderated by the ranks of, and tie strengths with, these associates.

A secondary objective of this study is to examine whether the gender composition of a network and strong ties to male associates have a differential effect on the ranks of male and female managers. Whether networking is a career enhancing activity has received very little empirical attention in the literature as it is usually assumed that networking matters. An exception here is Brass (1985) who found that the composition of one's network can affect one's promotion chances at work. The nature of the sample, however, precluded an examination of whether the promotion chances differ between males and females. In contrast, the data used in the present study allow for such a distinction

Another contribution of this study is that it allows us to assess whether female managers in Hong-Kong behave like their U.S. counterparts in their choice of network members. It has been argued that females seek out males to network with because the latter are more useful than female members. Given the cultural differences between Chinese and U.S. women, it is however unclear whether female managers in Hong-Kong will follow the same strategy in choosing their network members as their U.S. counterparts.

\section{FACTORS INFLUENCING EXPRESSIVE AND INSTRUMENTAL NETWORKS}

Both the similarity-attraction (Byrne, 1971) and the relational demography paradigms (Tsui et al., 1992) posit that individuals are attracted to those they are similar to. Thus, other things being equal, it is expected that women prefer to interact with other women and men prefer to network with other men. Put differently, both males and females are inclined to network with same sex associates. However, because of differences in gender socialization process in early childhood, it is argued that women are better at acknowledging and understanding the feelings of others (Gilligan, 1982) while men are more inclined to communicate in a self promoting and challenging style (Tannen, 1994). These studies therefore suggest that compared to men, women are better candidates to seek expressive and emotional support from. For men seeking expressive support, then, same-sex tie (or relationship) is not the most appropriate option in spite of gender similarity. Furthermore, the strength of ties between the ego and the associate can also be used as a criterion for choosing associates in expressive contents. Where the relationship between alter and ego is strong (defined here as strong ties), one would expect high levels of intimacy and frequent interactions between the ego and the associate (Bian, 1997). Such ties are therefore expected to be positively linked to expressive network. Thus, Hypothesis 1a: Same-sex ties will be positively related to female expressive network but not to male network.

Hypothesis 1b: Strong ties will however be positively related to both male and female expressive networks.

Ibarra (1992) argued that for instrumental contents, it is preferable for women to network with those in control of resources and promotion opportunities. Since those in power are predominantly males, women are therefore less likely to rely on same-sex ties to acquire instrumental benefits. This is further reinforced by the fact that irrespective of their actual competence, male managers are perceived to be more competent than their female counterparts (Broveman et al., 1972; Heilman et al., 1989). In this sense, they are perceived to be better at delivering the instrumental benefits. For females, then, the similarity attraction to other female associates is dampened by the perceived and actual ability of males in providing the instrumental benefits. Thus,

Hypothesis 2: Same-sex ties will be positively related to male instrumental network but not to female instrumental network.

Research in informal mentoring suggests that women have more difficulty finding mentors than men (Raggins and Cotton, 1991). Because of the shortage of high-ranking females in organizations and the resulting lack of female mentors (Couric, 1989; Ragins \& Cotton, 1999), women seeking instrumental support have to approach male mentors. This cross-gender mentoring relationship, however, faces more hurdles than a same-sex relationship. Fear of sexual intimacy prevents the cross-gender relationship to blossom (Feldman et al., 1999). Such a relationship is also more susceptible to damaging rumors of sexual involvement (Kram, 1985). Male protégés do not face such 
barriers and accordingly, have easier access to mentors. Further, since mentors are usually high-ranking officials in organizations (Ragins and Scandura, 1994), it therefore follows that compared to females, males are more likely to interact with higher-ranked associates for instrumental purposes. Thus,

Hypothesis 3: Higher-ranked associates will be positively related to male instrumental network only.

Network members with strong ties interact frequently and develop close, intimate and long-lasting relations. Because of the frequency of these interactions, information shared among strong ties tends to be redundant. Granovetter's seminal work on "the strength of weak ties" (1973) posits that weak ties are more beneficial than strong ties because they serve as bridges across social boundaries. More recent research, however, argues that strong ties also link individuals from different social status (Wegener, 1991). This is further supported by the evidence from the Chinese labor market (Bian, 1997) that strong ties are used more frequently than weak ties in job search. Strong ties also help network participants overcome any negative stereotype that they may be faced with (Ibarra, 1993). Since female managers are perceived to be less competent and influential than their male counterpart (Heilman et al., 1989; Brass, 1985), and are more likely to be at the receiving of negative stereotyping, they stand to benefit more from strong ties than males. Furthermore, Burt (1992) argued that strong ties with powerful individuals provide females with some measure of legitimacy in organizations. Altogether, these studies imply that strong ties yield instrumental benefits, with females gaining more from such ties. Thus,

Hypothesis 4: Strong ties will be positively related to both male and female instrumental network, with the effect being larger in the female case.

What remains unanswered is the effect of strong ties between associates and egos of the same sex. Aldrich (1989) argued that strong ties in same-sex cases are less beneficial in that the information from such interaction lacks diversity and tends to be redundant. Extending this argument, we contend that strong ties with other females are unlikely to provide female managers with the measure of legitimacy discussed above because males are usually the ones in position of power. Further, strong ties with females are unlikely to resolve the negative attribution problem faced by women managers. For these reasons, we argue that female managers are unlikely to derive any instrumental benefits from strong ties with other females. Thus,

Hypothesis 5: Strong ties with same-sex associates will be negatively related to both male and female instrumental networks, with the effect being larger in the female case.

While we do not expect females to approach higher ranked males because of the problems associated with cross-gender mentoring, we do however expect them to approach higher ranked females for instrumental purposes. Raggins and Scandura (1994) argue that same-sex mentoring is beneficial to both protégés and mentors. For the protégés, female mentors not only serve as a role model but also help avoid the difficulties usually encountered in cross-gender mentoring relationships. For the female mentors, mentoring other women helps satisfy their relationship needs (Raggins and Scandura, 1994) and is consistent with their gender role expectations (Eagly, 1987). Furthermore, because mentors tend to select protégés who are younger versions of themselves (Raggins and Cotton, 1999), female mentors who help other females may view this as helping another version of themselves. These arguments therefore suggest that for women seeking instrumental information, they will prefer to approach high ranking females who in turn welcome such interaction. This is also consistent with the similarity-attraction and relational demography propositions. Although the discussion on the benefits of same-sex mentoring has been in terms of female to female mentoring, the same argument can be applied to male to male mentoring. Thus,

Hypothesis 6: Higher ranked associates of the same gender will be positively related to both male and female instrumental network.

The relationships between the six hypotheses discussed so far can be depicted in Figure 1. The linkages in Figure 1 show that the effect of same sex ties on female instrumental network is more complex than has been hypothesized in previous research. Same sex ties have both a direct effect (H2 link) and indirect effects through their interactions with strong ties (H5 link) and with higher ranked associates (H6 link) on female instrumental network. The network literature has focused exclusively on the direct link whereas the present study examines both the direct and indirect effects. 
Figure 1: Factors Influencing Instrumental and Expressive Networks

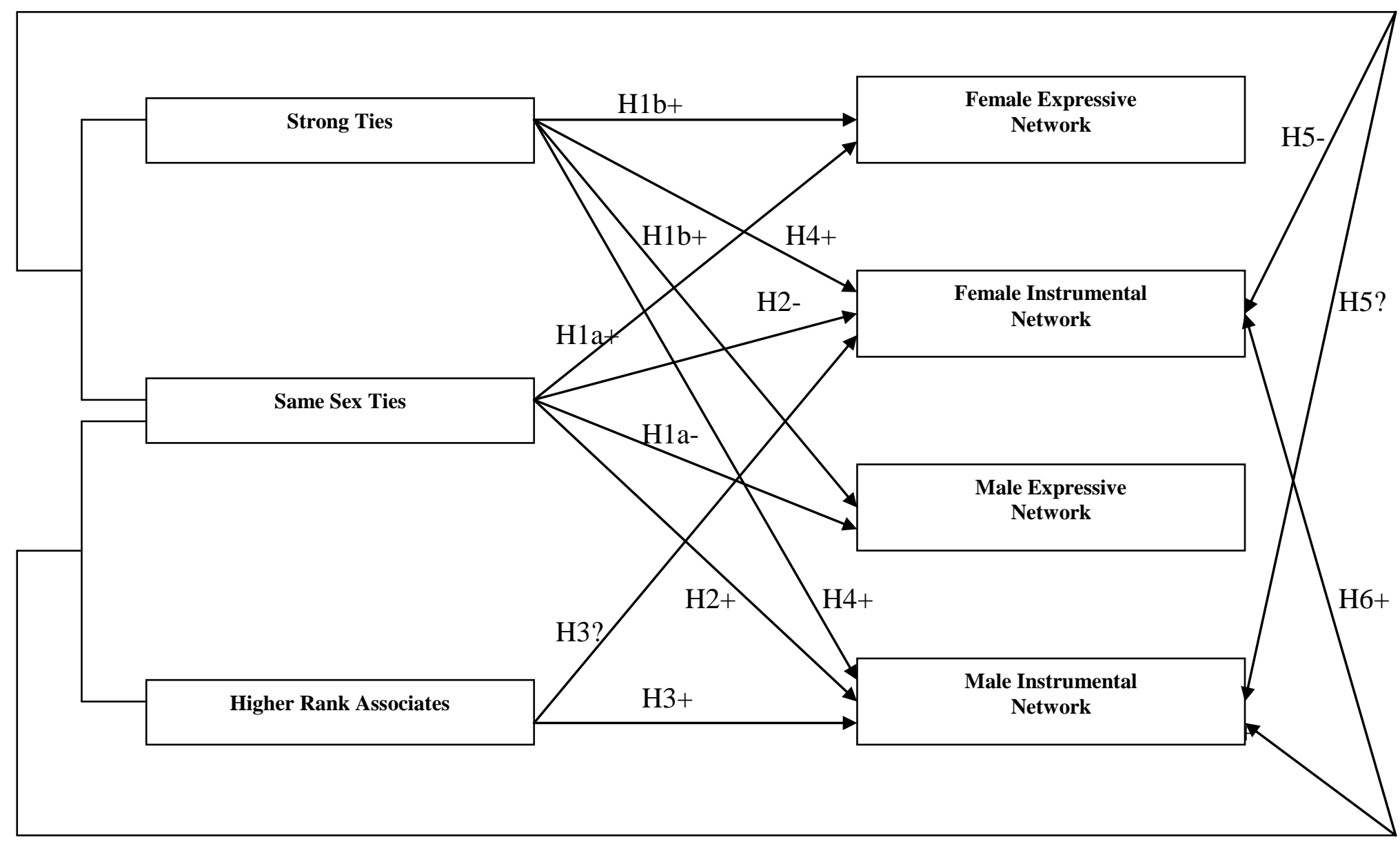


The final hypothesis of this study examines the effects of gender distribution in a network and of strong ties to male associates on the managerial ranks of egos. Consistent with the view espoused in the network analytic literature that promotion decisions are made predominantly by men (Brass, 1985), we argue that more males in a network provide the ego more opportunities to interact with, and catch the attention of, the decision-makers. This greater access to the decision-makers should provide egos not only with advance lead on career opportunities but also with insights as to what the ego can do to increase the probability of being chosen for the job. Thus, we expect that more males in a network to lead to higher managerial ranks. We further contend that a greater proportion of males in a network is more beneficial to female than male egos. In cross-gender ties, the information shared tends to be more diverse than in the case of same sex ties (Ibarra, 1997). To the extent that information diversity adds to one's promotion chances, female egos therefore derive greater benefits when interacting with male associates than male egos would.

Strong ties are associated with frequent interactions and high levels of intimacy (Bian, 1997). Thus, we expect strong ties with male network members to provide egos with more detailed information on career opportunities. These ties are therefore expected to be positively related to the managerial ranks of the egos. Given Burt's (1992) argument that strong ties to men provide women the legitimacy to get promoted, it can therefore be argued that the career enhancing benefit of strong ties to men are of greater value to female than male egos. Thus, Hypothesis 7: Managerial rank is positively related to the proportion of males in the network and to the strength of ties to these males. The impact will be larger for female than male respondents.

\section{DATA AND METHODS}

The data for this study were collected in Hong-Kong from 41 participants in an executive MBA program, 18 from a part-time MBA program and 13 from an executive development program for a local financial institution. Personal network information was obtained by asking the respondents to name 5 individuals for each of the following networks: (1) advice on a decision one has to make, (2) information about the organization, (3) influencing the outcome of an important decision, (4) personal crisis, and (5) friendship. Examples of name generating questions included "who would you turn to for important decision and needed advice?" and "who you socialize with after work?" Consistent with previous research, associates from the first three contents are considered to be instrumental ties while the last two are viewed as expressive ties. In addition to their own personal characteristics, the respondents were asked to identify the associate's demographic (age, gender, education level, marital status, etc.) and work characteristics, how close they are to each associate named, the number of years they have known each other, and the nature of their relationship such as close family, classmate, colleague, and so on.

\section{Sample Characteristics}

Of the 72 respondents, two-thirds are males, $74 \%$ are married and $82 \%$ have a university degree. Over $40 \%$ of the respondents are between 36 to 40 years old. The respondents were all employed full-time. On average, they had 14 years of work experience, been in their current organization for over 10 years, and in the current position for over 3 years. One-third of the respondents (35\%) have lived abroad for an average of over 5 years. Over $60 \%$ of them worked for locally owned organizations. The males and females included in the sample had slightly different profile. Men were relatively older, having longer work experience, occupying more senior position and supervising more subordinates. Aside from these, there was no other significant difference in the sample characteristics of male and female respondents.

The respondents identified a total of 1032 associates, of whom 280 are immediate family members. For the purpose of this paper, we exclude these individuals because the respondents informed us that close family members especially parents, are somewhat uneducated and are therefore rarely consulted on instrumental contents. These individuals are also quite distinct from the other network members in that close family members are in the network by default. Of the associates included in the analysis, 59\% are males, $68 \%$ are married and $72 \%$ have a university degree. The percentage of associates who are less than 30,31 to 35,36 to 40,41 to 45 , and over 45 years old are 18.5, $18.3,24.5,14.4$, and $24.3 \%$ respectively. Compared to the respondent group, the associate group has fewer males, is older and less educated. 
Table 1: Variable Definitions and Means by Gender

Variables

Male means

Female means

Expressive network: Extent to which alter is named for expressive network (Min $=0 ; \operatorname{Max}=2$ )

0.56

1.13

Instrumental network: Extent to which alter is named for instrumental contents (Min $=0$; Max =3)

Rank above $=1$ if alter is higher ranked than ego

Strong tie $=1$ if alter is especially close to ego

Same gender $=1$ if alter is same gender as ego

Same age $=1$ if alter is in same age category as ego

Same education $=1$ if alter has same educational as ego

Colleague $=1$ if alter and ego are in same organization

Common Bases: Extent to which alter and ego share Same clubs, classes and neighborhoods

$(\operatorname{Min}=0 ; \operatorname{Max}=3)$

Years known: Number of years ego has known alter
$0.25 \quad 0.30$

$0.25 \quad 0.33$

$0.75 \quad 0.53$

$0.29 \quad 0.40$

$0.28 \quad 0.33$

$0.60 \quad 0.59$

$0.42 \quad 0.40$

$9.27 \quad 7.08$

\section{Measures}

The variables used in the testing of the hypotheses are defined in Table 1. Expressive network measures the extent to which an associate is named for personal crisis and/or friendship contents ( $\min =0$ and $\max =2)$. Thus, if the associate is not named for any of these 2 contents, expressive network takes on the value of " 0 ". If the associate is named for both contents, then the variable takes on the value of " 2 ". Instrumental network measures the extent to which an associate is named for advice, information, and/or influence contents. If the associate is not identified with any of these contents, then the variable is set to " 0 ", and if the associate is identified with all 3 contents, then the variable is set to " 3 ".

Rank Above measures whether the associate is higher ranked than the respondent and it is set to "1" if the associate is higher ranked and " 0 " otherwise. Strong tie measures the strength of the relationship between the respondent and the associate and it is set to " 1 " if they are especially close. Same gender, same age and same education measure whether the associate and the respondent are of the same gender, same age bracket, and same educational level respectively. If they are, the corresponding variable takes on the value of "1". The variable, Colleague, is set to 1 if both the associate and the respondent work in the same organization. Common Base measures the extent to which the associate and the respondent live in the same neighborhood, belong to the same club, and/or were classmates. If they share all these 3 bases, then the variable is set to " 3 ". Otherwise, it is set to the number of bases that the respondent and the associate have in common. Years known measure the number of years the respondent has known the associate.

\section{Data Analysis}

For hypothesis 1 to 6 , the unit of analysis is by associates and we divided the associates into two groups those nominated by male respondents and those nominated by female respondents. We run a series of regression equations for the male and the female group separately. The definitions and means of the variables used in the equations are presented in Table I.

The dependent variables represent the number of times an associate has been nominated for either expressive or instrumental contents. The control variables include whether the respondent and alter are in the same age category, whether respondent and alter have the same educational level, number of years alter and ego have known each other, whether alter and respondent are colleagues, and extent to which alter and respondent share common bases. The variables of interest are whether respondent and associate are of the same gender, whether alter is higher ranked than respondent, and whether alter and respondent have strong ties. The statistical significance of these variables together with their interaction terms will determine whether hypotheses 1 to 6 are supported. 
To test hypothesis 7, regression analysis is also used but the unit of observation here is in terms of the respondents. The dependent variable is the managerial rank of the respondent, defined as the number of ranks below the manager's rank minus the number of ranks above the manager's, divided by the total number of ranks in the organization.

The control variables in the regression equation are years of work experience, gender, and education of the respondent, and the proportion of non-family members in the respondent's network. The variables of interest are the proportion of males in the network and the strength of ties with these male members. Whether hypothesis 7 is supported will depend on the statistical significance of these latter variables and their interactions with the gender of the respondent.

Table 2: Factors Influencing Expressive and Instrumental Networks Standardized Regression Coefficients ${ }^{\mathrm{a}}$

Dependent Variables

\begin{tabular}{|c|c|c|c|c|c|c|c|c|c|c|}
\hline \multirow[t]{2}{*}{$\begin{array}{l}\text { Independent } \\
\text { Variables: }\end{array}$} & \multicolumn{2}{|c|}{ Network Expressive } & \multicolumn{2}{|c|}{$\begin{array}{l}\text { Instrumental } \\
\text { Network (Eq. 1) }\end{array}$} & \multicolumn{2}{|c|}{$\begin{array}{l}\text { Instrumental } \\
\text { Network (Eq. 2) }\end{array}$} & \multicolumn{2}{|c|}{$\begin{array}{l}\text { Instrumental } \\
\text { Network (Eq.3) }\end{array}$} & \multicolumn{2}{|c|}{$\begin{array}{l}\text { Instrumental } \\
\text { Network (Eq. 4) }\end{array}$} \\
\hline & Male & Female & Male & Female & Male & Female & Male & Female & Male & Female \\
\hline Same gender & -.04 & $.09 *$ & $.11 * *$ & .02 & $.12 * *$ & .11 & $.15^{* *}$ & -.04 & .06 & -.12 \\
\hline Rank above & -.07 & -.06 & $.10^{*}$ & .11 & $.10^{*}$ & .11 & $.26 * *$ & .04 & .09 & $.14 *$ \\
\hline Strong tie & $.16^{* *}$ & $.25 * *$ & $.14^{* *}$ & $.31 * *$ & $.18^{* *}$ & $.45^{* *}$ & $.15^{* *}$ & $.31 * *$ & $.14 * *$ & $.31 * *$ \\
\hline Same age & -.04 & .05 & -.02 & .01 & -.02 & .01 & -.02 & .02 & -.02 & .02 \\
\hline Same education & -.04 & .07 & .04 & .10 & .04 & .10 & .03 & $.11^{*}$ & .04 & $.11 *$ \\
\hline Colleague & $-.40 * *$ & $-.49 * *$ & $.32 * *$ & $.39 * *$ & $.32 * *$ & $.40 * *$ & $33 * *$ & $.39 * *$ & $.27 * *$ & $.26^{* *}$ \\
\hline Common bases & $.08^{*}$ & .08 & .04 & -.11 & .04 & -.11 & .04 & $-.13 *$ & .04 & $-.12 *$ \\
\hline Years known & $.21 * *$ & $.11 * *$ & $.23 * *$ & $-.12 *$ & $-.22 * *$ & $-.11 *$ & $-.23 * *$ & -.11 & $-.23 * *$ & -.10 \\
\hline Same sex x Strong tie & ---- & ---- & ---- & ---- & -.05 & $-.22 *$ & ---- & ---- & ---- & ---- \\
\hline Same sex x Rank above & ---- & ---- & ---- & ---- & ---- & ---- & -.19 & .12 & ---- & ---- \\
\hline Same sex x Colleague & ---- & ---- & ---- & ---- & ---- & ---- & ---- & ---- & .08 & $.20 *$ \\
\hline Adjusted $\mathrm{R}^{2}$ & 0.41 & 0.59 & .24 & .30 & .23 & .31 & .23 & .30 & .23 & .31 \\
\hline
\end{tabular}

** represents significance at .001 level

* significance at .05 level.

\section{RESULTS}

The results of the regressions analyses for the associates are reported in Table II. The estimated coefficients for the expressive tie equation show that the same-sex variable is significant only for the female group. This therefore implies that male respondents do not show any preference for networking with male associates on expressive contents whereas women respondents prefer to network with other females on such contents. The positive and statistically significant coefficients for the strong tie variable implies that both male and female egos seek expressive support from associates they are close to. Hypothesis 1 is therefore supported.

The results from the instrumental equation (Equation 1) show that for instrumental contents, male respondents tend to network with other males whereas for women, there is no preference for same-sex interaction. This finding is consistent with, and therefore supports, hypothesis 2 . The results also show that compared to their female counterparts, male respondents are more likely to interact with higher ranked associates, thus providing support for hypothesis 3 . The estimated coefficients on tie strength show that for instrumental network, both male and female respondents are likely to approach associates whom they have strong ties with. Further, the size of the estimated coefficients in the male and female equations implies that a strong tie associate is more likely to be approached by females than males. Hypothesis 4 is therefore supported by these findings. 
Hypothesis 5, which states that both males and females are unlikely to approach strong ties of the same sex for instrumental purposes, is partially supported. The estimated coefficient for the interaction term between strength of ties and same sex (Equation 2 of Table II) shows that while males are indifferent to male associates they are strongly tied to, females are less likely to approach other females whom they have strong ties with. Thus, the prediction of hypothesis 5 is supported for the female respondents only.

Hypothesis 6, which states that both males and females are likely to approach higher ranked associates of the same sex, is not supported. The estimated coefficient for the interaction between rank and same-sex (Equation 3 of Table II) is not significant for both males and females. This suggests that the respondents do not show any preference in the gender of higher ranked associates when the latter are approached for instrumental purposes. Because of the lack of high ranking female mentors, Kram and Isabella (1985) and Noe (1988) suggested that women should perhaps seek instrumental support from their peers. To test for this possibility, we developed another interaction, the product of colleagues and same-sex, measuring same-sex colleague. We added this interaction term to the original equation and the results (Equation 4) show that while men do not show any preference for other male colleagues when seeking instrumental ties, females do prefer to deal with other female colleagues.

The regression result of equation 1 in Table III indicates that the managerial rank of the respondent is unaffected by the proportion of males in the network. Strong ties with males in the network are positively related to rank but the relationship is only marginally significant at the .1 level. Overall, the empirical evidence provides only marginal support for hypothesis 7. To examine whether network composition and ties to males affect male and female respondents differently, we added two interaction terms in the original regression equation. The first interaction term, strong ties with male associates multiplied by the sex of the respondent, is not significant, implying that the benefits from strong ties with male associates are similar for both male and female respondents.

The second interaction term, proportion of males in the network multiplied by the gender of the respondent, is statistically significant and positively related to managerial rank. Thus, contrary to expectations, male respondents are more likely to gain from having a higher percentage of males in the network. Furthermore, following Jaccard et al. (1990), the estimated coefficient for the proportion of males variable in regression equation 2 can be interpreted as the effect of that variable on the managerial rank of females. The estimated negative and statistically significant coefficient therefore implies that for females, a higher proportion of males in their network have a negative effect on their managerial rank.

\section{DISCUSSION AND CONCLUSION}

The primary objective of this study has been to examine the extent to which males and females differ in terms of who they approach for expressive and instrumental contents. The results show that for expressive contents, both men and women seek to network with those they have strong ties with. The results also indicate that women prefer to network with other women whereas men show no gender bias. This finding therefore supports the conventional view that because women are better at understanding others' emotions (Gilligan, 1982), men do not seek emotional ties from other men in spite of their gender similarity.

The results for instrumental contents show that women are quite rational in terms of how they interact with other women. Consistent with Ibarra (1992), the female respondents do not seek same-sex ties for instrumental network because women in general do not hold positions of power and are underrepresented in managerial positions. Further, because the information from close-ties females is redundant (Aldrich, 1989), the female respondents in our study do not approach those they have strong ties with for instrumental information. On the other hand, in the absence of interaction with high-ranking females, our female respondents seek instrumental support from other female colleagues. This behavior pattern is consistent with the suggestion from the mentoring literature that where same-sex mentoring is not available, females should focus on peer relationship (Noe, 1988). Thus, our study shows that the gender selectivity of the female respondents goes beyond a simple choice between males or females. Where it is beneficial, the female respondents choose cross-gender ties. In other instances, they prefer same sex ties, even for instrumental purposes. 
Table 3: Factors Affecting Management Rank Standardized Coefficient Reported

Dependent variable is management rank $^{\mathrm{a}}$

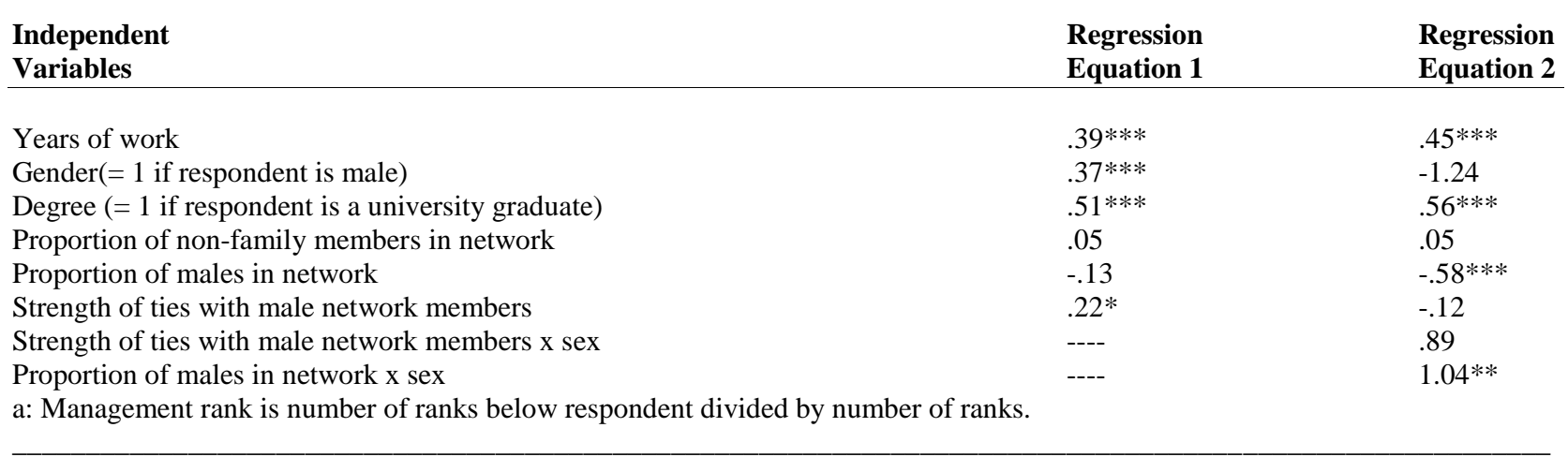

*** denotes significance at .01 level,

** significance at .05 level

$*$ at .1 level.

It is expected culture differences lead to different networking behaviours. Given the consistency between the results of this study with those of earlier studies, it can be argued that in spite of cultural differences, female managers from Hong-Kong are just as rational as their counterparts from the United States. One possible explanation is the selection of sample specific bias of MBA students. Managers enrolled in MBA programs are more upwardly mobile, perhaps more westernized than many other groups of Chinese. Further, because of the changes in Hong Kong Chinese society and their impact on the roles of women, the latter are no longer treated as subordinate to men and confined to domestic work as in the past (Pearson, 1996; de Loen \& Ho, 1994; Westwood et al., 1997). In addition, according to the GLOBE study, Hong Kong is very similar in terms of gender egalitarianism as other Western societies (House et al., 1999). These studies therefore suggest that the changing environment in Hong-Kong has provided the Chinese female managers the same kind of opportunities as their colleagues in the West.

Contrary to the strength of weak ties argument (Granovetter, 1973), our study shows that both males and females are likely to interact with those they have strong ties with. This result therefore provides additional support for the recent studies (Wegener, 1991; Bian, 1997) which argue that strong ties are also useful. Combining this result with the earlier finding that the female respondents do not seek instrumental support from female associates whom they have strong ties with implies that female respondents seek instrumental support from strong ties males. A possible explanation here is that with strong ties, there is less negative attribution towards the respondents (Ibarra, 1993), and are likely to be taken more seriously by their male associates.

The results of our study also show that unlike their male counterparts, the female respondents do not approach higher ranked associates for instrumental contents. While this is understandable in cases where the associates are males because of the potential problems associated with cross-gender mentoring, we however found that this is also the case for higher-ranked females. One possible explanation for this unexpected finding is that junior female managers may not want to join other women, even if the latter are higher ranked, if women as a group are perceived to be of low status (Ely, 1994). This is however unlikely given that Hong-Kong is high on gender equality in the 1999 Globe study. A more plausible explanation is that there were not that many higher-ranked female associates in the female network. The data show that the 24 female respondents named a total of 103 higher ranked associates (about $30 \%$ of the network), of whom only 35 are females. Since several of the female respondents named 2 to 3 higher ranked females, this meant that a number of female respondents did not have access to higher ranked females after all. This lack of higher ranked female associates also explains why the female respondents turned to female peers for instrumental network. This may not be their preference but this is what is available to them. 
Another objective of this study has been to examine whether the sex composition in a network together with strong ties with male associates have an impact on the managerial ranks of the respondents. The result indicates that strong ties to males have a marginal but positive effect on managerial ranks. The proportion of males in the network however appears to have no impact on ranks. Further investigation, however, shows that more male associates in a network is positively related to the rank of male respondents and negatively related to the rank of female respondents. While our finding seems to contradict Brass (1985) who found that access to men's network was positively correlated to promotion, we argue that this is not the case. In the latter study, males and females were not analyzed separately and because of the small number of females being promoted, it is difficult to assess whether the results based on the entire sample were applicable to female promotion cases. If the results were in fact representative of males' promotion cases, then our result is consistent with Brass (1985), at least for the male respondents.

The above discussion however still begs the question of why women's career mobility is impeded by ties to men. Extending the argument on the barriers associated with cross-gender mentoring (Raggins and Cotton, 1999) to other cross-gender relationships, we argue that it is difficult for men and women to develop a close working relationship. Cross-gender ties are therefore typically weak ties. It therefore follows that a network with a higher proportion of the opposite sex is a network of weak ties. Such network structure is detrimental to women because it does not provide them with the legitimacy needed for promotion (Burt, 1992). Further, male associates with weak ties are more likely to hold on to whatever negative stereotype they have of women (Berger et al., 1977). Information flowing from this source is likely to be less useful in helping women in their career growth. These arguments together with our finding that there is a marginal but positive relationship between ranks and strong ties suggest that it is not men per se that is needed to enhance the mobility of women. Rather, it is strong ties to men that matter. This however poses a major challenge for female managers because the difficulties associated with cross-gender relationships make it difficult to develop strong ties with males.

The implication from the above is that if left on their own, women managers find it difficult to develop the right network that can help them break through the glass ceiling. The corollary then is that for organizations serious in helping women move up in the organizational hierarchy, a formal mentoring system should be implemented. The design should be such that it fosters the development of close ties between the mentor and the subordinate, and that it should be transparent enough to dispel of any rumors of sexual improprieties.

Given that cultivating and maintaining network takes a lot of time and effort, it is important to formulate strategies on how to maximize value. The results showing that having a large number of male network members does not help the managerial ranks of females therefore suggest that females managers should develop their network more strategically, focusing on those who are better able at providing instrumental benefits .

The under-representation of women in top management positions, together with women's reluctant to approach higher rank associates put women in isolated and disadvantage positions. The present study shows that the networking behaviors impose negative effect on same sex instrumental ties for women. As a result, women will have lower level of social exchange and lower quality of mentoring. Another implication of this study is to focus organizational efforts on improving the problems facing women. Organization should make a concerted effort of elevating qualified women to management level to provide lower ranked women an alternative source for their instrumental help and career advancement.

\section{Limitations And Future Research Directions}

Given the dearth of research on how networking affects the career mobility of females, further research would be useful in identifying potential relationships between career growth and other network analytic factors such as network diversity and centrality. Ibarra (1995) found that racial minorities seeking other similar associates tend to network beyond their immediate work group in their search for such ties. To the extent that women exhibit the same behavior pattern, research is needed to identify how network outside the immediate work unit affects the upward mobility of women in the organization. Further, in spite of the link between network centrality and promotion (Brass, 1985), further empirical support is needed given the small number of promotion cases analyzed in that study. Finally, there is a need to fine-tune our finding that the career growth of women is inversely related to the proportion of men in 
the network. While there are several reasons as to why this may be the case, it does not mean that women should exclude men from their network. After all, even weak ties have their own usefulness (Bian, 1997). What remains to be explored then is the optimum number of men needed in a woman's network to satisfy her career aspirations.

Despite the consistency of some of the findings of this study with past research, the reader should be careful in interpreting our results. The cross-sectional nature of data makes it difficult to assign causality. In addition, since the data is nonrandom, care should be exercised in generalizing the finding of this study. Finally, there is the potential problem of reverse causality. We hypothesized that network composition has an influence on managerial ranks. It is however possible that managerial ranks also have an impact on network composition. Because of this, there is a potential upward bias in the estimated impact of network composition on ranks. For this reason, one should treat our analysis of network and career mobility with caution.

\section{REFERENCES}

1. Adler, N. J. Competitive frontiers: Women managers in the triad, International Studies of Management and Organization, Vol. 23, No.2, pp.3-23, 1993.

2. Aldrich, H. Networking among Women Entrepreneurs. In Hagan, O., Rivchun, C., and Sexton, D. (Eds.), Women-owned businesses, New York: Praeger, pp.103-132, 1989.

3. Auster, E. R. Demystifying the glass ceiling: Organizational and interpersonal dynamics of gender bias, Business and the Contemporary World, Vol.5, pp.47-68, 1993.

4. Berger, J.; Fisek, R.; Norman, Z., and Zelditch, Jr. M. Status characteristics and social interaction: An expectation states approach. New York: Elsevier, 1977.

5. Bian, Y. Bringing strong ties back in: Indirect ties, network bridges, and job searches in China, American Sociological Review, Vol.62, pp.366-385, 1997.

6. Brass, D. J.. Men's and women's networks: A study of interaction patterns and influence in an organization, Academy of Management Journal, Vol. 28, No.2, pp.327-343, 1985.

7. Broverman, I. K., Vogel, S., Broverman, D. M., Clarkson, F E., and Rosencrantz, P. S. Sex Role Stereotypes: A Current Appraisal, Journal of Social Issues, Vol.28, No.2, 9-78, 1972.

8. Burt, R. S. Structural holes: The social structure of competition. Cambridge, MA: Harvard University Press, 1992.

9. $\quad$ Byrne, D. The attraction paradigm. New York: Academic Press, 1971.

10. Couric, E. Women in the large firms: A high price of admission? National Law Journal, vol.11, No.2-3, 10$12,1989$.

11. de Leon, C. T. and Ho, S. The third identity of modern Chinese women: Women in Hong Kong, In Adler, N. J. and Izraeli, D. N. (eds.), Competitive frontiers: Women managers in a global economy. Cambridge, MA: Blackwell, pp.3-21, 1994.

12. Eagly, A. H. Sex differences in social behavior: A social-role interpretation. Hillsdale, NJ: Erlbaum, 1987.

13. Ely, R. J. The effects of organizational demographics and social identity on relationships among professional women, Administrative Science Quarterly, Vol.39, pp.203-238, 1994.

14. Feldman, D. C., Folks, W. R, and Turnley, W. H. Mentor-protege diversity and its impact on international internship experiences, Journal of Organizational Behavior, Vol.20, pp. 597-611, 1999.

15. Gilligan, C. In a different voice: Psychological theory and women's development. Cambridge, MA: Harvard University Press, 1982.

16. Granovetter, M. The strength of weak ties, American Journal of Sociology, Vol.6, pp.1360-1380, 1973.

17. Heilman, M. E.; Block, C. J.; Martell, R. F., and Simon, M. C. Has anything changed? Current characterizations of men, women, and managers, Journal of Applied Psychology, Vol.74, No.6, pp. 935-942, 1989.

18. House, R. J., Hanges, P.J. Ruiz-Quintanilla, S. A., et al. Cultural influences on leadership and organizations:

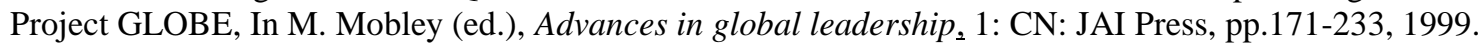

19. Ibarra, H. Homophily and differential returns: Sex differences in network structure and access in an advertising firm, Administrative Science Quarterly, Vol.37, pp.422-447, 1992.

20. Ibarra, H. Personal networks of women and minorities in management: A conceptual framework, Academy of Management Review, Vol.18, No.1, pp.56-87, 1993. 
21. Ibarra, H. Race, opportunity, diversity of social circles in managerial networks, Academy of Management Journal, Vol.38, pp.673-703, 1995.

22. Ibarra, H. Paying an alternative route: Gender differences in managerial networks, Social Psychology Quarterly, Vol.60, N0.1, pp.91-102, 1997.

23. Jaccard, J., Turrisi, R. and Wan, C.K. Interaction effects in multiple regression. Beverly Hills: Sage, 1990.

24. Kanter, R. M. Men and women of the corporation. New York: Basic, 1977.

25. Kram, K. E. Mentoring at work. Glenview, IL: Scott Foresman, 1985.

26. Kram, K. E. and Isabella, L. Mentoring alternatives: The role of peer relationships in career development, Academy of Management Journal, vol.28, pp.110-132, 1985.

27. Moore, G. Structural determinants of men's and women's personal networks, American Sociological Review, Vol.55, pp.726-735, 1990.

28. Morrison, A. M., White, R. P. and Van Velsor, E. Breaking the glass ceiling: Can women reach the top of America's largest corporations? Addison-Wesley Publishing Co., 1987.

29. Noe, R. A. Women and mentoring: A review and research agenda, Academy of Management Review, Vol.13, pp.65-78, 1988.

30. Oakley, J. G. Gender-based barriers to senior management positions: Understanding the scarcity of female CEOs, Journal of Business Ethics, Vol.27, No.4, pp.321-334, 2000.

31. Pearson, V. The past in another country: Hong Kong women in transition, Annuals of the American Academy, Vol.547, pp.91-301, 1996.

32. Ragins, B. R., and Cotton, J. L. Easier said than done: Gender differences in perceived barriers to gaining a mentor, Academy of Management Journal, Vol.34, No.4, pp.939-951, 1991.

33. Ragins, B. R., and Scandura, T. A. Gender differences in expected outcomes of mentoring relationships, Academy of Management Journal, Vol.37, No.4, pp.957-971, 1994.

34. Ragins, B. R., Townsend, B. and Mattis, M. Gender gap in the executive suite: CEOs and female executives report on breaking the glass ceiling, Academy of Management Executive, Vol.12, No.1, pp.28-42, 1998.

35. Ragins, B. R., and Cotton, J. L. Mentor functions and outcomes: A comparison of men and women in formal and informal mentoring relationships, Journal of Applied Psychology, Vol.84, No.4, pp.529-550, 1999.

36. Tannen, D. Talking from 9 to 5: How women's and men's conversational styles affect who gets heard, who gets credit, and what gets done. New York: William Morrow \& Co., 1994.

37. Tsui, A., Egan, T. D. and O'Reilly, C. A. Being different: Relational demography and organizational attachment, Administrative Science Quarterly, Vol.37, pp.549-579, 1992.

38. Wegener, B. Job mobility and social ties: Social resources, prior job, and status attainment, American Sociological Review, Vol.56, pp.60-71, 1991.

39. Westwood, R. I., Ngo, H. and Leung, S. The politics of opportunity: Gender and work in Hong Kong. Part 1: The gendered segmentation of the labor market, In Cheung, F. M. (ed), Engendering Hong Kong society, The Chinese University Press, Hong Kong, pp.41-99, 1997. 